\title{
Detection of Seasonal Trends in Vegetation Cover in Kogi State: Guinea Savannah Region of Nigeria Using Time Series MODIS NDVI Data
}

\author{
Babatunde OSUNMADEWA and Christine WESSOLLEK \\ TU Dresden / Germany·babatunde_adeniyi.osunmadewa@mailbox.tu-dresden.de \\ This contribution was double-blind reviewed as full paper.
}

\begin{abstract}
Natural vegetation is an important source of livelihood for rural communities living in the savannah region of Nigeria. Apart from the direct benefit derived from vegetation exploration, vegetation also is of vital importance in environmental processes such as protecting soil against erosion and maintaining the carbon cycle. Due to human perturbation and inherent climate variability, there has been an increasing decline in vegetation productivity over the last decades in the guinea savannah region of Nigeria. Hence, there is an urgent need to carry out research on seasonal trends of vegetation pattern using reliable techniques, especially in Nigeria where population is growing at a fast rate, and the dependency on vegetation for means of livelihood is high. This paper analyses the trends in vegetation greenness in Kogi state, Nigeria, using seasonal trend analysis (STA) to extract information from the monthly MODIS NDVI (Terra) data from 2000 to 2010 in four different locations. The results show considerable variations in the period of greening (start and end of greening) from the four different locations in Kogi state, a situation which implies that there is a shift in vegetation types in this ecological zone. This is taken to be a consequence of human interference due to the pattern of agricultural intensification and urban expansion over the years. Although, seasonal trend analysis is a robust means of analyzing trends in vegetation, this paper suggests that other indicators such as soil aridity, climatic data and land-use pattern should be included for further analysis in order to uncover human-induced loss of vegetation cover in the guinea savannah region of Nigeria.
\end{abstract}

\section{Introduction}

Vegetation cover plays a key role in terrestrial biophysical processes being the nutritional basis for higher organisms such as animals and man. Vegetation as the main component of the terrestrial biosphere is a crucial element in the climate system (FOLEY et al. 2000), hence; there is high confidence that global warming is now strongly affecting the terrestrial biosphere (IPCC 2007). Human actions, especially those involving biomass fuel consumption, land-use change, and agricultural activities, cause direct interaction with the land surface, which has negative consequences on vegetation and environmental qualities.

Vogler, R., Car, A., Strobl, J. \& Griesebner, G. (Eds.) (2014): GI_Forum 2014. Geospatial Innovation for Society. (C) Herbert Wichmann Verlag, VDE VERLAG GMBH, Berlin/Offenbach. ISBN 978-3-87907-545-4.

(C) ÖAW Verlag, Wien. eISBN 978-3-7001-7652-7, doi:10.1553/giscience2014s91. 
These interactions are rather complex and have attracted research interest in the last four decades (GOLDEWIJK \& RAMANKUTTY 2010). The Global Forest Resources Assessment of 2010 conducted by the United Nations Food and Agricultural Organisation (FAO 2010a), however, estimated forested areas in West Africa at 74.25 million hectares; corresponding to about $11 \%$ of the total land area in the sub region and $0.02 \%$ of global forest area. Similarly, a regional analysis of the same assessment revealed that as at 1990, the total forested area in West Africa was 91,589,000 hectares, which was reduced to 81979,000 hectares in the year 2000, and 73234,000 hectares in 2010. By implication, these records indicate an annual rate of change of $-1.10 \%$ in the $1990-2000$ period, and $-1.12 \%$ in the 2000-2010 period. This trend, according to BENTON (2010), ClARKE \& CRAME (2010) and LYONS et al. (2010), is the result of past environmental conditions and evolutionary constraints undergone by world vegetal cover.

To proficiently address these new challenges, development of new techniques and tools to quantify and provide explanation for the change are obligatory (CHAO et al. 2010, GOTELLI et al. 2010, MAGURRAN \& HENDERSON 2010). In Nigeria, the eco-climatic and agroecological zones (AEZ) have currently been going through noticeable transition due to large scale land-cover transformations across the country. A change assessment computed by ADEOFUN et al. (2011) using national land-use/land-cover classification data of 1995 by the Forestry Monitoring, Evaluation and Coordinating Unit (FORMECU) of the Federal Ministry of Forestry, revealed large scale transition just within twenty years. The study revealed that several physiognomic units have assumed identities different from the popular descriptions of the past. The many indications of increased perturbation of natural forest cover such as forest fragmentation by government road projects, increased fuel wood and timber consumption, increased human and livestock population, increases in number of enclaves within the forest zones with the attendant pressure on the forest resources, and alteration in the local weather pattern, have been quite instructive in the new vegetal-cover characterization observed throughout the country at present. These land-use changes appear to have been accompanied by the changes in the magnitude and timing of vegetation greenup (NEETI et al. 2012). This study therefore takes advantage of the availability of vegetation data derived from NASA's Moderate Resolution Imaging Spectroradiometer (MODIS Terra vegetation indices, "MOD13C2") to examine the trends in terrestrial ecosystem dynamics over the last one decade (LP DAAC 2009).

As the world's terrestrial ecosystem is going through monumental perturbations from natural and anthropogenic sources, the Kogi state vegetation pattern presents substantive evidence of the resulting transition. At present, the terrestrial ecosystem has been profoundly affected, so that the need for a vegetation assessment using a reliable and fast technique has become very important. The natural resources of the country do not grow similarly, and continue to be degraded and depleted due to the increasing demands of people (and their associated industries) for water, food, fuel, and income. Meanwhile, there has been a long recess in vegetation mapping and classification in Nigeria as a whole. The problem emanating from this transcends a mere gap in knowledge. Since the conundrum of outdated information about environmental conditions often manifests in grave issues like biodiversity loss, failure of the agricultural sector and other habitat loss induced environmental issues, adequate knowledge about ecosystem response to environmental changes becomes vital. 
The aim of this paper is to detect changes in vegetation trend (greenness) in the Guinea savannah region of Nigeria using MODIS NDVI data.

\section{Description of Study Area}

As the human population continues to increase, information on vegetation that is both spatially comprehensive and of appropriate resolution is becoming more vital for effective management of our biological resources (BINO et al. 2008). The population of the study area (Kogi sate) is mostly rural and had increased tremendously over the last decades from 2,147,756 in 1991 to 3,314,043 in 2006 (NATIONAL BUREAU OF STATISTICS 2010).Thus, this upsurge in population has a resulting effect on the depletion of the greenbelts and wetlands within- and the degradation of vegetation outside the metropolis. The need to assess the change in vegetation is an important starting point for environmental management. The use of remotely sensed data provides comprehensive spatio-temporal portraits of mid- to long-term (years to decades) vegetation dynamics, especially with fine temporal resolution data from the Advanced Very High Resolution Radiometer (AVHRR) (TUCKER et al. 1985) and Moderate Resolution Imaging Spectroradiometer (MODIS) (HuETE et al. 2002 in NeETI et al. 2012). Kogi state (Nigeria) is located between latitude $8^{\circ} 44.64^{\prime} \mathrm{N}$ and $6^{\circ} 32.02^{\prime} \mathrm{N}$ and longitude $5^{\circ} 20.97^{\prime} \mathrm{E}$ and $7^{\circ} 50.59^{\prime} \mathrm{E}$, bordered by Niger state to the north, Ekiti state to the west, Benue state to the east, and Anambra state to the south.

Seasonal trend analysis is an improved method to analyze seasonal trends in time series data, which can potentially identify vegetation change while characterizing interaction at different temporal scales (EASTMAN et al. 2009). This study uses Seasonal Trend Analysis (STA) for detecting inter-annual, annual and semi-annual patterns of changes in the vegetal-cover of Kogi state, Nigeria using monthly MODIS data from 2000-2010. These changes are related to modification in land-use practices vis a vis climatic variability in the region.

\section{Methodology}

\subsection{Data}

Seasonal trend analysis (STA) of vegetation dynamics/change over a large area requires time series Earth Observation (EO) data acquired from sensors with high temporal resolution covering a wider area. However, annual variability in vegetation condition can be influenced by climate fluctuations, for example, rainfall, and anthropogenic activities such as agriculture and urbanization. Time series of remotely sensed data can be used for analyzing seasonal trends using different types of method such as fourier transformation, harmonic analysis, and logistic functions. Thus, the monthly MODIS NDVI Terra (MOD13C2) product (spatial resolution: $0.05^{\circ}$ ) acquired from Land Processes Distributed Active Archive Center (LP DAAC) were used for this study. The monthly MODIS Terra NDVI product was used based on a previous study of vegetation analysis in the whole of Nigeria (OYEDEPO 2011 unpublished), which will be improved on for further studies in the future. Other ancillary data used are a land use land cover map from FORMECU (1976 and 1996) and TAMSAT rainfall data (2000-2010) of the study area. 


\subsection{Methods}

\subsubsection{Image Pre-Processing}

The monthly MODIS NDVI data were re-projected from the global projection (-180 to $+180,-90$ to +90 global extent) to Universal Transverse Mercator (UTM). Subset images of the study area were clipped out of the global data using the Kogi state provincial provisional boundary. Noise (cloud, effects of satellite sensors, off NADIR angles and atmospheric contaminations), which is one of the major challenges in seasonal trend data was reduced during processing of the time-series analysis. This was done by subjecting the time series to two harmonic regression analyses, which operate independently on each pixel over time. Two frequencies are used for the harmonic regression in order to capture the dominant trends in the data without including high frequency noise (EASTMAN et al. 2009). The Theil-Sen median was also applied in order to resist the impacts of outliers. However, the original values $(-2,000$ to 10,000$)$ of this data were not altered.

\subsubsection{Seasonal Trend Analysis (STA)}

Changing trends in seasonal patterns of NDVI data ('greenness' of vegetated land cover) were analyzed using STA. The STA, however, uses two stages of time series analysis, which are preceded by a final stage of visualization. STA performs a harmonic regression of yearly images. Thus, two harmonics were used in order to provide generalization of the seasonal curve, that balances the need of describing the basic structure of the time series, while avoiding excessive influence from noise, (EASTMAN et al. 2009) this is referred to as the first stage in the time series analysis. Amplitude 0 represents overall greenness or the mean annual NDVI for each year, amplitude 1 represents the peak of annual greenness (annual cycle), while phase 1 can be referred to as the timing of annual peak greenness and also the semi-annual cycle (Amplitude 2 and Phase 2). Slope, intercept and significance images are produced as well as composites for phase and amplitude which is the second stage. This second stage involves calculating the temporal trend in greenness parameter; it is done by calculating the linear trend of each pixel using all pairwise combinations of images in time, and takes the median of all slopes to create a slope image for each of the greenness parameters (HOAGLIN et al. 2000). The produced maps were then interpreted by extracting seasonality curves and subsequently the phonological parameters from the curves.

More detailed information about the basic concept of seasonal trend analysis can be found in EASTMAN et al. (2009).

\section{$4 \quad$ Results}

It is difficult to directly interpret the produced seasonal maps; however, by using interpretational aids, the amplitude or phase trend images can be meaningfully deduced. Thus, areas that are going through similar trends in seasonality can be located, and areas that have no trend can also be identified. Colour composites of the three amplitude images derived from STA, which is referred to as the amplitude trend image, provide the greatest amount of information, especially about the phenology of vegetation. 
For this study, we developed an interactive interpretational aid in which area of interests (cf. Fig. 1) were delineated by defining a circular region, because of the complexity in interpreting the image produced by STA (harmonic parameters). Examination of trends in vegetation change pattern was based on a green up/ green down approach. Thereby, green up refers to the time of maximum greening, while green down is the time of maximum loss of green in vegetation.

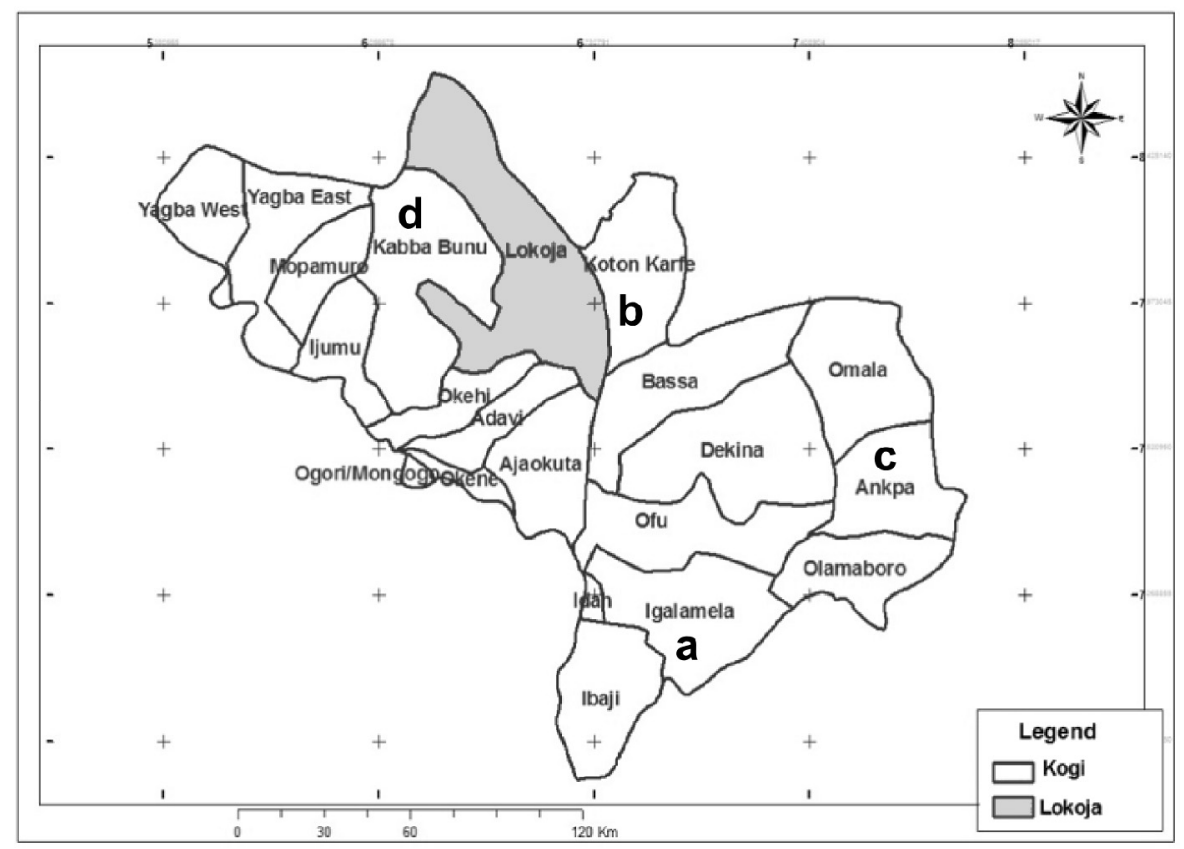

Fig. 1: Administrative map of Kogi state showing the four selected locations (a-d)

Graphs of seasonal trend analysis of monthly NDVI from the MODIS dataset (2000 2010) were produced from the harmonic regression of STA. A graph of observed values and fitted values plotted against time of the year generates seasonal curves of both the observed and fitted (smoothed) trend. The graph shows the year from January through to December on the x-axis, and NDVI on the y-axis. The two lines in the fitted seasonal curve graph are like fitted regression lines, and indicate generalized statements of the seasonal curves for the start and the end of the series. The fitted seasonal curves graph the modelled seasonal curve for the first (light grey) and last (dark grey) year of the series, while the observed seasonal curves graph the actual values of the curves for the period of time specified in the analysis (number of years in first/last median images).

The fitted curves are derived mathematically from the entire series and represent the very first year and last year of the series and observed curves are summaries of observed values over a user-specified period of time. The observed curves are noisier and represent a shorter series than the fitted curves. 
As can be seen from the fitted curve in location a (cf. Fig. 2), vegetation greening-up started earlier in 2010 (April) than in 2000 (June), and greening down started earlier in 2010 (early February) than in 2000. The differences observed in the fitted curve (2010) occurred at the peak of the agricultural season, where there is indiscriminate removal of trees (natural forest) for agriculture purposes. Thus, the two peaks (2010) are in relation with the cultivation method/pattern which is typical for the study area (i.e. two growing seasons). To better understand the shift in seasonal cycle (greenness), it is appropriate to compare the results of the fitted curve with the observed curve and meteorological precipitation data.

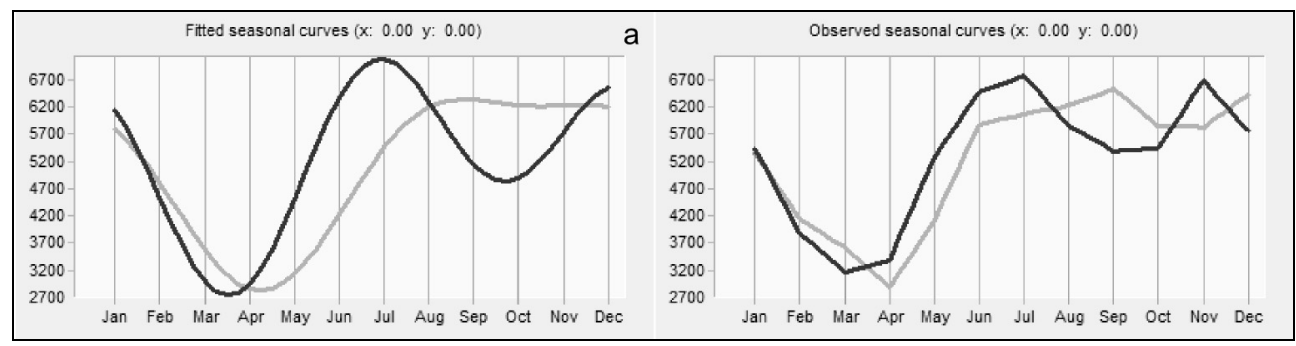

Fig. 2: Fitted and observed seasonal curves of NDVI derived from trends over the complete series for Igalamela-odolu LGA, Kogi state (2010 dark grey and 2000 light grey)

For location $b$ (cf. Fig. 3) the start of greening-up for both years is almost the same. The result derived during the STA shows that greening-up started earlier in 2000 (May 16) as compared to 2010 (May 13), while greening-down also started earlier in 2000 (Jan 27) than in 2010 (Jan 30). Though there seems to be no significant difference in greening-up and greening-down dates for 2000 and 2010, the fitted curve shows that there is a longer greening period for 2000 than 2010. This may be interpreted in two ways: either a longer rain season, or undisturbed vegetal cover in the study area in 2000.

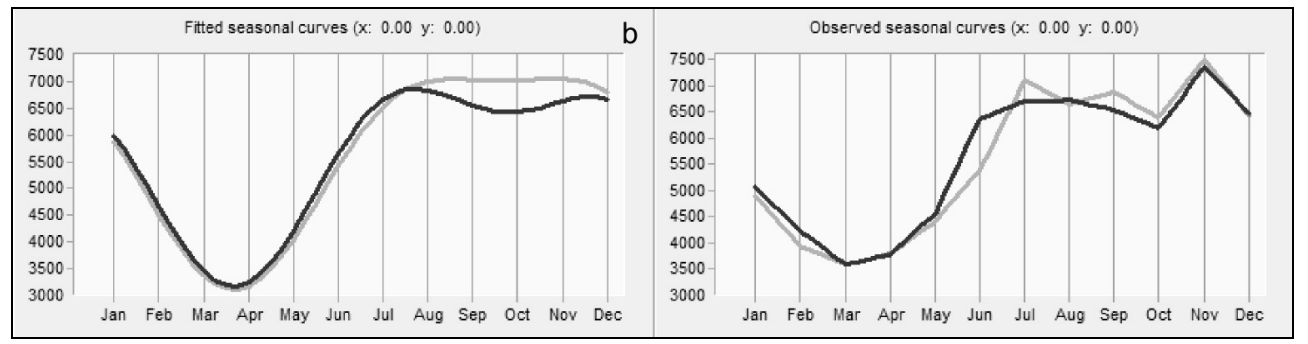

Fig. 3: Fitted and observed seasonal curves of NDVI derived from trends over the complete series for Koton- karfe LGA, Kogi state (2010 dark grey and 2000 light grey)

For location c (cf. Fig. 4) the curve between the beginning and the end of the series shows that annual greenness started earlier in 2000 (May), which is the start of the wet season in the study area, and ends in early January when compared with 2010 . It is observed that 
there is a greater increase in greening period at the start of the series (2000) than at the end of the series (2010).

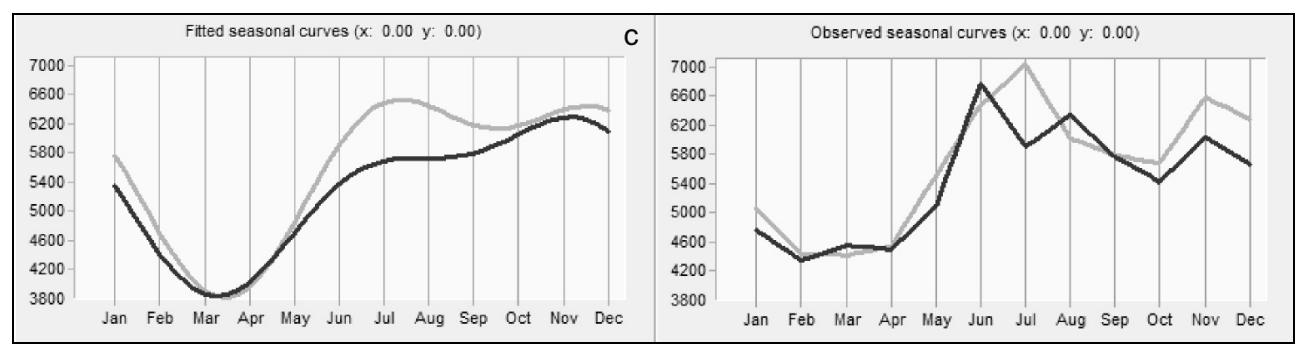

Fig. 4: Fitted and observed seasonal curves of NDVI derived from trends over the complete series for Ankpa LGA, Kogi state (2010 dark grey and 2000 light grey)

Location $d$ (cf. Fig. 5) is characterized by nomads and farmers whose life dependency is on the forest. The gap observed in the greening down date for the end of the series in the observed seasonal graph (2010) between July and September might therefore be attributed to continuous grazing of livestock in the area at the expense of the vegetation cover during the August dry spell.

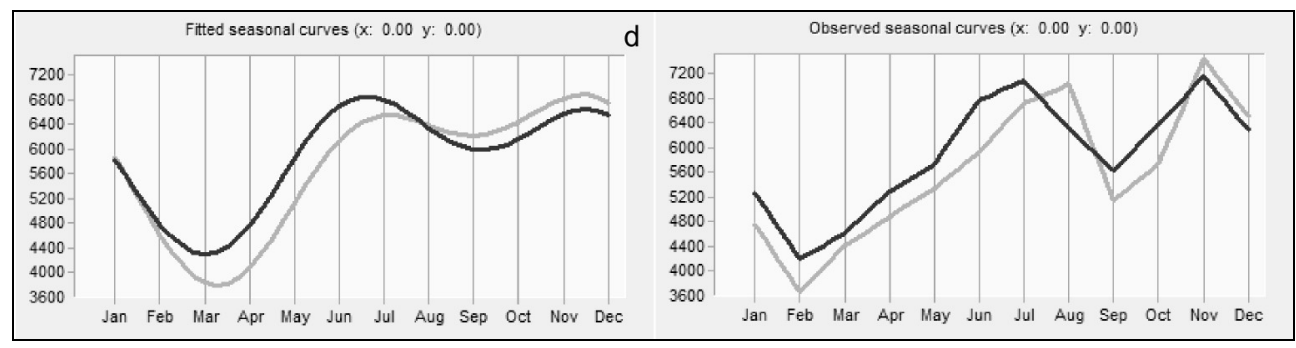

Fig. 5: Fitted and observed seasonal curves of NDVI derived from trends over the complete series for Kabba/Bunu LGA, Kogi state (2010 dark grey and 2000 light grey)

Although these four profiles cover only a small part of the whole study area, it can be seen that there are changes in seasonal trend of vegetation pattern, depending on the location of the chosen profiles.

\section{Discussion}

In order to understand the results derived from the seasonal trend analysis, other ancillary data on land use land cover and rainfall for the period 2000-2010 of the study area were analyzed. The land use land cover data used for this study was derived from the forestry monitoring and evaluation coordinating unit (FORMECU). Land use as one of the major drivers of vegetation change for 1976 and 1995 was analyzed, and the results are presented 
in Table 1. Analysis of the data shows reduction in vegetation types during the two seasons; this is evident from the results of fresh water march/swamp, riparian forest and undisturbed forest respectively. Conversion to other land use types such as built-up-area and agricultural land is attributed to a high population growth rate from 2,147,756 in 1991 to 3,314,043 in 2006 (FGEG 2007). NATHANIEL (2012) revealed in his study of LULC for Kogi state that there was a decrease of about $-50.9 \%$ in vegetation cover between 1986 and 2007. This conversion of vegetation into other land use land cover, coupled with climatic variation, has influence on vegetation greening-up and greening-down of the study area and this can be seen from the STA results in figure 3.

Results of rainfall plotted against time for the study area shows slight variation in rainfall pattern for the period of 2000 to 2010 . Another interpretation for the two peaks of greeningup and greening-down observed in the fitted curve for 2010 (Fig.2) can be attributed to the peak of agricultural activities, where the first seasonal cultivation and harvesting take place between April- August while the second seasonal cultivation starts in September for some crops. Hence, changes in vegetation greening should not only be explained by climatic variability, but also with other factors such as land use land cover change. Further analysis on the correlation coefficient between vegetation and rainfall needed to be carried out in further study.

Tab. 1: Land-use and land cover distribution of Kogi state 1986 and 1995

\begin{tabular}{|c|c|c|}
\hline Land cover categories & $\begin{array}{c}\mathbf{1 9 7 6} \\
\mathbf{A r e a ~}\left(\mathbf{K m}^{\mathbf{2}}\right)\end{array}$ & $\begin{array}{c}\mathbf{1 9 9 5} \\
\mathbf{A r e a}\left(\mathbf{K m}^{\mathbf{2}}\right)\end{array}$ \\
\hline Agricultural land & 21902.65 & 23081.94 \\
\hline Built-up-area & 20.77 & 124.23 \\
\hline Disturbed forest & 568.76 & 299.94 \\
\hline Forest plantation & 2.20 & 39.14 \\
\hline Fresh water march/swamp & 1319.37 & 333.32 \\
\hline Riparian forest & 1777.46 & 1027.92 \\
\hline Rock outcrop/un-vegetated area & 73.11 & 65.10 \\
\hline Tree crop plantation & 1.63 & 1.60 \\
\hline Undisturbed forest & 1142.26 & 427.22 \\
\hline Water body & 5.17 & 73.88 \\
\hline Woodland savannah & 2097.00 & 3100.22 \\
\hline Grassland & 57.56 & 393.43 \\
\hline Total & $\mathbf{2 8 9 6 7 . 9 4}$ & $\mathbf{2 8 9 6 7 . 9 4}$ \\
\hline
\end{tabular}

\section{Conclusion and Outlook}

As biological production is important to livelihood systems in most semi-humid zones, improved knowledge of the functioning and monitoring of changes in vegetation greenness and productivity is crucial. In order to better understand changes in greening pattern of the 
study area (Kogi state), a seasonal trend analytical approach was used to delineate long term trends in the character of seasonal curves using a MODIS 10 year dataset. Thus, annual phenologies may shift as a result of climate change and large scale anthropogenic disturbance over a longer time period, as this is observed from the result of the land use land cover change of the study area (Table 1) and rainfall. It is observed from the result of the study that the greening up stars earlier in Kabba/Bunu (location d) as compared to the other locations.

This study demonstrates the ability of STA as an effective tool for detecting vegetation change patterns in an ecologically sensitive zone, which can be used for further study on the relationship between greenness of vegetation, anthropogenic factors, and climatic variability in the Guinea savannah region of Nigeria. As human population increases, substantial changes in NDVI become apparent. Results of this study thus show changes in annual greenness and timing of greening events which correspond to the land use land cover pattern for the whole study area. As the vegetation greening-up and greening-down sometimes does not correspond with the precipitation pattern, more analysis and adequate knowledge on the interrelationship between vegetation and environmental parameters such as solar radiation, air temperature, rainfall and soil aridity are very important for trends in vegetation dynamics. To bridge this gap, updated information on the phenological pattern of various divisions of Nigerian vegetation with reliable information on the vegetal cover with respect to local climate variation is needed.

This paper therefore suggests further assessment of seasonal trends in vegetation with the use of medium scale spatial and high temporal resolution data such as MODIS 16-days composite $250 \mathrm{~m}$ NDVI data, LANDSAT or Terra Aster imagery, climatic data (precipitation and temperature) and demographic data for proper modelling of vegetation change patterns in the study area. Results of such modelling will serve as an early warning measure against desertification processes for the study area in the future.

\section{References}

Adeofun, C. O., Oyedepo, J. A. \& Ogunsesan, A. A. (2011), Assessment of Human perturbation of Nigerian terrestrial ecosystems. An Unpublished research paper for presentation at the 12th CEST international Conference on Science and Technology in Greece.

Benton, M. J. (2010), The origins of modern biodiversity on land. Phil. Trans. R. Soc. B, $365,3667-3679$.

Bino, G., Levin, N., DARAwshi, S., VAn Der hal N., SOlOMOn, A. R. \& KARK, S. (2008), Accurate Prediction of Birds Species Richness Pattern in an Urban Environment using Landsat-derived NDVI and Spectral Unmixing. International Journal of Remote Sensing, 29 (13), 3675-3700.

ChaO, A., ChIU, C.-H. \& Jost, L. (2010), Phylogenetic diversity measures based on Hill numbers. Phil. Trans. R. Soc. B., 365, 3599-3609.

Clarke, A. \& CRAME, J. A. (2010), Evolutionary dynamics at high latitudes: speciation and extinction in polar marine faunas. Phil. Trans. R. Soc. B, 365, 3655-3666. 
Eastman, J. R., Sangermano, F., Ghimire, B., Zhu, H., Chen, H., Neeti, N., Cai, Y., MACHAdO, E. A. \& CREMA, S. C. (2009), Seasonal trend analysis of image time series. International Journal of Remote Sensing, 30, 2721-2726.

Foley, J. A., Levis, S., CostA, M. H., Cramer, W. \& Pollard, D. (2000), Incorporating dynamic vegetation cover within global climate models. Ecological Applications, 10, 1620-1632.

Food And Agriculture Organisation of the United NAtions (FAO, Rome) (2010a), Global forest resources assessment, 2010 - Main report. FAO Forestry Paper, 163. Rome, Italy (also available at www.fao.org/forestry/fra/fra2010/en/).

FORESTRY MONITORING AND EVALUATION COORDINATING UNIT (FORMECU) (1998), The assessment of vegetation and land use changes in Nigeria between 1976/78 and 1993/95.

GoldEWIJK, K. K. \& RAMANKUTTY, N. (2010), Land use changes during the past 300 years. Land Use, Land Cover and Soil Sciences, 1.

Gotelli, N. J., Dorazio, R. M., Ellison, A. M., Grossman, G. D. (2010), Detecting temporal trends in species assemblages with bootstrapping procedures and hierarchical models. Phil. Trans. R. Soc. B, 365, 3621-3631.

Hoaglin, D. C., Mosteller, F. \& Tukey, J. W. (2000), Understanding Robust and Exploratory Data Analysis, 160-170. New York, John Wiley.

Huete, A., Didan, K., Miura, T., Rodriguez, E. P., GaO, X. \& Ferreira, L.G. (2002), Overview of the radiometric and biophysical performance of the MODIS vegetation indices. Remote Sensing of Environment, 83, 195-213.

IPCC (2007), Synthesis Report 4th Assessment report of the intergovernmental panel on climate change (pp. 52).

LP DAAC (2009), Land Processes Distributed Active Archive Center. https://lpdaac.usgs.gov/products/modis_products_table/mod13c2.

LyONS, S. K., WAGNER P. J. \& DZIKIEWICZ, K. (2010), Ecological correlates of range shifts of Late Pleistocene mammals. Phil. Trans. R. Soc. B, 365, 3681-3693.

Magurran, A. E. \& Henderson, P. A. (2010), Temporal turn-over and the maintenance of diversity in ecological assemblages. Phil. Trans. R. Soc. B, 365, 3611-3620.

National Bureau of Statistics (2010), Annual abstract of statistics 2010, Federal Republic of Nigeria. www.nigerianstat.gov.ng.

NATHANIEL, O. A. (2012), Spatio-Temporal Analysis of Land Use/ Cover Change of Lokoja - A Confluence Town. Journal of Geography and Geology, 4. ISSN 1916-9779; E-ISSN 1916- 9787 (published by Canadian Centre of Science and Education).

Neeti, N., Rogan, J., Christman, Z., Eastman, J. R., Millones, M., Schneider, L., Nickl, E., Schmook, B., Turner II, B. L. \& GHimire, B. (2012), Mapping seasonal trends in vegetation using AVHRR-NDVI time series in the Yucatán Peninsula, Mexico. Remote Sensing Letters, 3 (5), 433-442.

OYEDEPO, J. A. (2011), An Assessment of vegetal-cover transition in Nigeria using temporal analysis of satellite-derived data (unpublished).

TUCKER, C. J., TOWNSHEND, J. R. G. \& GOFF, T. E. (1985), African land-cover classification using satellite data. Science, 227, 369-375. 